\title{
New Loss of Viable Myocardium by Non- invasive Imaging Technique
}

National Cancer Institute

\section{Source}

National Cancer Institute. New Loss of Viable Myocardium by Non-invasive Imaging

Technique. NCI Thesaurus. Code C119213.

A finding of loss of viable myocardium, which is new compared to prior non-invasive imaging techniques. 